\title{
Erratum to: Laser Polishing of Additive Manufactured AlSi10Mg Parts with an Oscillating Laser Beam
}

Jochen Schanz, Markus Hofele, Leonhard Hitzler, Markus Merkel and Harald Riegel

Erratum to:

Chapter "Laser Polishing of Additive Manufactured AlSi10Mg Parts with an Oscillating Laser Beam" in: A. Öchsner and H. Altenbach (eds.), Machining, Joining and Modifications of Advanced Materials, Advanced Structured Materials 61, DOI 10.1007/978-981-10-1082-8_16

The affiliations of two authors: Markus Merkel and Harald Riegel were modified from Chapter "Laser Polishing of Additive Manufactured AlSi10Mg Parts with an Oscillating Laser Beam" post-publication. The erratum chapter and the book have been updated with correct affiliation of the authors in Chapter "Laser Polishing of Additive Manufactured AlSi10Mg Parts with an Oscillating Laser Beam”.

The updated original online version for this chapter can be found at 10.1007/978-981-10-1082-8_16

J. Schanz $(\square) \cdot$ M. Hofele $\cdot$ M. Merkel $\cdot$ H. Riegel

Aalen University of Applied Sciences, Beethovenstraße 1, 73430 Aalen, Germany

e-mail: jochen.schanz@hs-aalen.de

M. Hofele

e-mail: markus.hofele@hs-aalen.de

M. Merkel

e-mail: markus.merkel@hs-aalen.de

H. Riegel

e-mail: harald.riegel@hs-aalen.de

L. Hitzler

School of Engineering, Griffith University, Gold Coast Campus, Southport 4222, Australia

e-mail: leonhard.hitzler@griffithuni.edu.au 